\title{
A INTELIGÊNCIA COMPETITIVA NO CONTEXTO DAS STARTUPS DA COMUNIDADE SAN PEDRO VALLEY: PROPOSIÇÃO DE UM MODELO DE MATURIDADE
}

Frederico Cesar Mafra Pereira $^{1}$

Patrícia Silva Ribeiro ${ }^{2}$

${ }^{1}$ PPG GOC / Programa de Pós Graduação em Gestão \& Organização do Conhecimento / Universidade Federal de Minas Gerais

${ }^{2}$ Mestrado Profissional em Administração / Faculdade / FPL Educacional 


\section{A INTELIGÊNCIA COMPETITIVA NO CONTEXTO DAS STARTUPS DA COMUNIDADE SAN PEDRO VALLEY: PROPOSIÇÃO DE UM MODELO DE MATURIDADE}

Resumo: Este estudo teve como objetivos: i) identificar como as startups da Comunidade San Pedro Valley acompanham/monitoram seu ambiente de negócios; ii) identificar seu nível de conhecimento sobre IC e seus processos e; iii) propor um modelo para averiguação do grau de maturidade em IC a ser adotado pelas startups. Foi realizado estudo de múltiplos casos, de natureza descritiva quantitativa, envolvendo 93 startups, selecionadas via amostragem não probabilística por conveniência. Os resultados demonstram que as startups possuem práticas pouco estruturadas e não formalizadas de IC, principalmente quanto à coleta e análise de informações. A proposição do modelo para aferição do grau de maturidade em IC se constituiu na principal contribuição da pesquisa, permitindo uma avaliação quantitativa até então só possível via critérios qualitativos e subjetivos da literatura. As startups obtiveram grau 2,40, no limite entre o nível 'iniciante' e o 'estruturado', dada as características de serem mais orgânicas e menos estruturadas.

Palavras-chave: Inteligência Competitiva. Grau de Maturidade em IC. Startups. Comunidade San Pedro Valley.

\section{Introdução e Contextualização}

A Inteligência Competitiva (IC) sustenta as organizações na tomada de decisões mais assertivas, visando bons resultados e performance de mercado (Gomes \& Braga, 2004). Sua utilização consiste num conjunto de metodologias para a produção de conhecimento sobre mercados, competidores, produtos, tecnologias e diversos outros pontos de relevância que surgem a partir de uma necessidade da organização (Teixeira \& Souza, 2017), sendo caracterizada tanto como um processo organizacional formalizado, estabelecido e cíclico, quanto uma prática de geração de conhecimento (Terra, 2005; Passos, 2007; Alvarenga Neto, 2008; Capuano, Casaes \& Costa, 2009; Starec, 2012; Pereira, 2013; Mafra Pereira, Jeunon, Barbosa \& Duarte, 2018; Mafra Pereira, Carvalho, Jordão \& Borges, 2018). Seu desenvolvimento auxilia as empresas a superarem as incertezas ambientas (Rodrigues, Volp \& Rechziegel, 2014), possibilitando o acesso às informações-chave do seu ecossistema. Assim sendo, é papel da IC indicar as rotas alternativas que evitarão perigos em potencial e aproveitar as táticas e estratégias que levam ao sucesso final (SCIP, 2019). Algumas empresas monitoram seu ambiente de maneira informal, já outras estabelecem processos bem estruturados de supervisão. Entre aquelas que não praticam e as que investem na IC existem níveis, ou graus de maturidade, sendo que, quanto maior o grau, maior a sua capacidade competitiva (Rodrigues \& Riccardi, 2007). Portanto, a sistematização da IC, esteja ela em qualquer nível, faz parte da estrutura da maioria das empresas. Segundo o SEBRAE (2019), as empresas de grande porte tendem a possuir um SIC mais estruturado e formal, que se assemelha às definições e modelos preconizados pela literatura. Mesmo assim, trabalhos recentes demonstram que a IC vem se desenvolvendo no universo dos pequenos negócios, como em Vitorino e Garcia (2013), Pereira e Perez (2015), Coutinho e Ramos (2015), Mafra Pereira e Santos (2015) e Oliveira e Sade (2016). Esse cenário, entretanto, não é comum em 
organizações do tipo startup, o que já apresenta uma importante lacuna teórica e aplicada deste trabalho. Estas são empresas com modelo de negócio escalável, equipe enxuta e custos reduzidos, e possuem base tecnológica e estratégia voltadas para a inovação, em condições de extrema incerteza (Ries, 2012). Por esse motivo, seria essencial o monitoramento de mercado a partir de processos que permitissem embasar tomadas de decisões quase sempre sob pressão. Para uma startup, a preocupação é desenvolver um produto/serviço que se adeque às necessidades do consumidor, sendo todas as decisões tomadas pelo empreendedor, que atua como o cérebro da organização (Pinheiro, 2016). Entretanto, por conceito e característica, atinge crescimento rápido e necessita mudar sua estrutura informal inicial para manter-se em funcionamento com eficiência (Blank, 2015). Contrariamente, nesse cenário nem sempre existem estruturas de IC para monitoramento de mercado, o que explica o percentual de mortalidade de 73,68\% de startups com mais de cinco anos de funcionamento (Startup Base Public Stats, 2019). Ter processos de IC estruturados deveria fazer parte do universo das startups, permitindo que decisões fossem tomadas de maneira assertiva, evitando taxas elevadas de mortalidade, melhorando a percepção do cenário de negócios, e contribuindo para sua evolução. Uma estratégia utilizada pelas startups é de se unirem em redes de negócios objetivando fortalecer suas condições de competição, criando parcerias com programas do governo, aceleradoras, sociedade e comunidades. Recentes estudos apresentam casos de sucesso sobre a proposição e aplicação/uso da IC em organizações complexas (associações, arranjos produtivos locais e redes interorganizacionais setoriais), como os de Garcia, Bessi e Reis (2013), Andrade, Fachinelli e Larentis (2015), Mafra Pereira, Jeunon, Barbosa e Duarte (2018), Mafra Pereira, Carvalho e Jordão (2016) e Mafra Pereira, Carvalho, Jordão e Borges (2018). Especificamente em Minas Gerais, a Comunidade San Pedro Valley estabelece uma cultura de empreendedorismo e inovação que fortalece o ambiente de negócios das startups ligadas ao setor de Tecnologia da Informação (TI). Sediada no bairro São Pedro, em Belo Horizonte, faz parte do ecossistema de inovação do Estado de Minas Gerais.

Com base no contexto apresentado, esta pesquisa teve como objetivos: i) identificar como as startups da Comunidade San Pedro Valley acompanham/monitoram seu ambiente de negócios; ii) identificar seu nível de conhecimento sobre a IC e seus processos (comparativamente aos modelos de IC propostos pela literatura) e; iii) propor um modelo para averiguação do grau de maturidade em IC a ser adotado pelas startups, sendo esta a principal contribuição teórica deste estudo. Além disso, os resultados pretendidos irão agregar à comunidade acadêmica conhecimento sobre o uso e grau de aplicação da IC no contexto das startups, em contraponto à maior parte das pesquisas sobre IC se concentrar em organizações de grande porte ou empresas com modelos de negócios tradicionais, mesmo sendo estas de pequeno porte. Dada a importância e representatividade para a economia nacional dos pequenos negócios (SEBRAE, 2019), e o crescente aspecto estratégico do tema da IC, contribui para a gestão das startups, ressaltando-se práticas inovadoras em IC, de forma sistêmica e formal, com vistas a tomadas de decisão mais assertivas para alcance de vantagem competitiva, mais sustentável e duradoura, com resultados eficientes, mensuráveis e gerenciados sistematicamente. Ainda, tem relevância na medida em que busca conhecer, cientificamente, sobre práticas informacionais estratégicas das startups da Comunidade San Pedro Valley e sobre o conhecimento dos seus empreendedores a respeito de práticas inovadoras de gestão das informações estratégicas que possam levar à vantagem competitiva. 


\section{Inteligência Competitiva: histórico, evolução e conceitos}

Prescott e Miller (2002) apontam que a origem da IC se relaciona às práticas e conhecimentos militares, e posteriormente, o mercado tomou para si tais ensinamentos e adaptou-os ao desenvolver um conjunto de conceitos e referências. No Brasil, as práticas de IC ganharam força quando as empresas se viram enfraquecidas para enfrentar a forte concorrência internacional durante a década de 1990 (Gomes \& Braga, 2004). Com a entrada de mais empresas estrangeiras no Brasil, aumentou-se a concorrência e as empresas nacionais se viram incitadas a investirem em IC para garantirem sua sobrevivência. Na academia, um dos marcos na IC no Brasil aconteceu em 1997, com a criação do $1^{\circ}$ Curso de Especialização em Inteligência Competitiva (CEIC) (ABRAIC, 2018). O tema ganhou força na comunidade acadêmica e em 2000 o CEIC foi lecionado em cinco cidades brasileiras, originando uma rede de especialistas que mais tarde se organizaram em associações, congressos, fóruns e debates (Amaral, Brito, Lima, Rocha \& Quoniam, 2016). Com relação aos conceitos, a literatura sobre este assunto aponta variadas referências. Mafra Pereira, Carvalho, Jordão e Borges (2018) apresentam uma compilação de conceitos da IC e sua evolução ao longo do tempo, a qual, por questões de tamanho, não será apresentada neste trabalho, ficando aqui a recomendação para sua consulta. Em suma, pode-se definir a IC como um processo estruturado e sistemático de coleta, análise e disseminação da informação oriunda do ambiente de negócios de uma organização, a ser utilizada como subsídio para a tomada de decisões estratégicas. Esta definição será considerada neste estudo como síntese da evolução conceitual da IC.

\section{Metodologias para estruturação da IC em empresas}

Baierle, Frozza, Nara e Kipper (2011) afirmam que os gestores se deparam diariamente com uma diversidade de dados, mas não conseguem filtrá-los para transformá-los em informação relevante e prioritária para a tomada de decisões complexas, sendo esta a principal finalidade de um produto elaborado por um SIC. Por isso, é fundamental que esteja localizado o mais próximo possível do tomador de decisão, sem burocracias que atrapalhem o desenrolar do processo (Gomes \& Braga, 2004). Além disso, precisa ter força dentro da organização para que seu produto ofereça valor agregado. Prescott e Miller (2002) argumentam que para a IC ganhar credibilidade dos usuários são necessários três pontos-chave: i) executar um trabalho emoldurado por uma ferramenta analítica, sendo, portanto, essencial o uso intensivo de TI; ii) dispor de uma comunicação eficaz para dominar a análise; iii) não possuir falhas técnicas, sob o risco de perder a total confiança. Oliveira, Gonçalves e Mendes de Paula (2011) opinam que uma estrutura adequada de processos e de profissionais deve ser capaz de fornecer os insights necessários para que a organização mantenha crescimento sustentável ao longo do tempo.

A IC pode ser estruturada por meio de ciclos/etapas organizadas com o objetivo de buscar a informação necessária e sistemática para direcionar a tomada de decisão, e diversos autores definem o que seria um "Ciclo de Inteligência" ideal, variando no número de etapas/subprocessos, como Martre (1994), Herring (1999), Canongia, Lamb, Carvalho e Silva (2001), Miller (2002), Bernhardt (2004), Gomes e Braga (2004), Motte (2007), Rodrigues e Riccardi (2007), Dishman e Calof (2008), Calof e Wright (2008), Panizzon (2010), Oliveira, Gonçalves e Mendes de Paula (2011) e Starec (2012). Mafra Pereira, Carvalho, Jordão e Borges (2018), em estudo propositivo de um modelo de estruturação da IC a ser adotado por Centrais de Negócios, adotaram o modelo de Amaral, Garcia, Faria e Aliprandini (2008) 
como ponto de partida, propondo um Ciclo de IC constituído de 6 etapas: 1) Identificação das Necessidades Informacionais; 2) Planejamento do Processo de IC; 3) Coleta das Informações; 4) Análise das Informações (Inteligência); 5) Disseminação da Inteligência e; 6) Avaliação da IC (Fig. 1), utilizado como marco teórico deste trabalho.

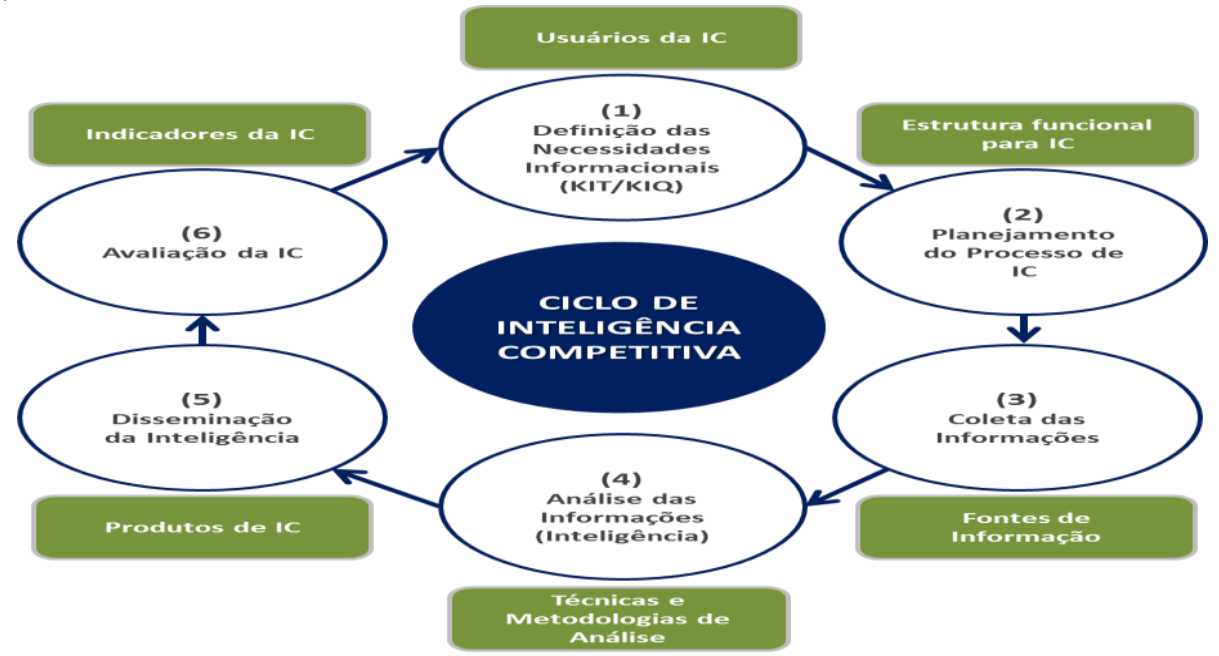

Figura 1 - Ciclo de Inteligência Competitiva

Fonte: Mafra Pereira, Carvalho, Jordão e Borges (2018).

Segundo Mafra Pereira et al. (2018), a $1^{\text {a }}$ etapa corresponde à 'Definição das Necessidades Informacionais', geradora dos KIT (Key Intelligence Topics) e KIQ (Key Intelligence Questions) (Herring, 1999; Prescott \& Miller, 2002). Estes proporcionam foco e priorização da IC para temas considerados estratégicos e relevantes pela organização (Canongia et al., 2001), ajudando na sua estruturação. Basicamente, são construídos a partir de 3 categorias (Herring, 1999; Canongia et al., 2001): i) temas de monitoramento ambiental; ii) atores-chave do ambiente de negócios; iii) decisões e ações estratégicas e táticas. Mafra Pereira et al. (2018) reforçam que essas categorias não são mutuamente exclusivas, podendo ser trabalhadas em conjunto e de forma interativa e integrada. Portanto, as necessidades informacionais são consideradas as reais necessidades de Inteligência, referentes às principais decisões que uma organização deverá tomar para a busca de vantagem competitiva em seu ambiente de negócios (Gomes \& Braga, 2004), e por isso, seus decisores são considerados os principais usuários-chave da IC (Herring, 1999). Este autor afirma que os gestores precisam da Inteligência, mas muitas vezes não compreendem como definir o que precisam. A $2^{\mathrm{a}}$ etapa corresponde ao 'Planejamento do Processo de IC', definindo-se a estrutura funcional necessária e a forma como o trabalho será desenvolvido: atividades, fontes de informação para a etapa de 'Coleta', métodos analíticos para a etapa de 'Análise', equipe envolvida, prazos para entrega dos produtos de IC, e recursos necessários (humanos, financeiros e estruturais) (Herring, 1999; Gomes \& Braga, 2004; Oliveira et al., 2011; Rodrigues, Rechziegel, Esteves \& Riscarolli, 2012; Mafra Pereira, Jeunon, Barbosa \& Duarte, 2018). Na $3^{\text {a }}$ etapa, de 'Coleta das Informações', são realizadas as etapas de busca, adequação e processamento das informações úteis à resolução dos KIT e KIQ definidos, a partir de fontes de informações relevantes e confiáveis, internas e externas à empresa, e de tipologias diversas (pessoais, documentais, eletrônicas, etc.) (Mafra Pereira, 2016), via instrumentos e procedimentos 
previamente estruturados (Canongia et al., 2001; Gomes \& Braga, 2004; Oliveira et al., 2011; Rodrigues et al., 2012). Gomes e Braga (2004) e Baierle et al. (2011) destacam que os dados e informações levantados são "inteligência bruta" e precisarão ser trabalhados para que possam ser utilizados na formulação de estratégias e tomada de decisões.

$\mathrm{Na} 4^{\mathrm{a}}$ etapa, de 'Análise das Informações', os dados e informações são transformados, de fato, em Inteligência. Para Mafra Pereira et al. (2018), esta etapa caracteriza-se como o 'coração' da IC, pois as informações transformadas em avaliações significativas visarão seu impacto na busca de posição competitiva da organização. Oliveira et al. (2011) destacam ser comum o uso de softwares e modelos estatísticos para demonstrarem as relações entre os padrões e tendências levantados, e Baierle et al. (2011) alertam que, mesmo no caso do processo de IC ser automatizado, somente o raciocínio humano é capaz de avaliar a relevância e a credibilidade das informações, sendo este um dos pontos mais críticos da IC. A fase de 'Disseminação da Inteligência' ( $5^{\text {a }}$ etapa) é caracterizada pela entrega tangível dos produtos de IC aos decisores (Gomes \& Braga, 2004; Oliveira et al., 2011; Rodrigues et al., 2012). Para Mafra Pereira et al. (2018), envolve a definição das estratégias de comunicação e disponibilização da Inteligência aos usuários da IC, conforme perfis e preferências, considerando formatos e mecanismos de distribuição, linguagem, abrangência e definição da frequência de envio destes produtos (Oliveira et al., 2011; Rodrigues et al., 2012). Nesta etapa ocorre também a apresentação das alternativas de ações, considerando-se suas limitações em executá-las e a reação mais provável do ambiente a cada uma delas. A última etapa é a 'Avaliação da IC', quando a preocupação é reconhecer e validar o processo junto aos usuários e decisores, fortalecendo o caráter de comprometimento e parceria entre eles. Mafra Pereira et al. (2018) advertem que não só é importante avaliar se a atividade de IC está cumprindo com planejado em termos de trabalho e entregas, mas também perceber e medir se está efetivamente sendo utilizada nos processos decisórios da organização; se é considerada estratégica pelos usuários que fazem uso dela. Baierle et al. (2011) afirmam que a 'Avaliação' é imprescindível para o constante desenvolvimento e aprimoramento do processo e para a sua própria sobrevivência, uma vez que a IC só se consolida quando seus resultados são efetivamente utilizados para a tomada de decisões empresariais. Essa visão do Ciclo de IC como fomento para processos decisórios pode variar em empresas jovens, maduras ou mais avançadas no seu ciclo de vida empresarial (Rodrigues et al., 2014), podendo a IC atingir, portanto, níveis de maturidade distintos conforme esses parâmetros.

\section{Grau de Maturidade em Inteligência Competitiva}

A realização do processo de IC exige da organização árduo compromisso em normatizar e padronizar seus procedimentos com o objetivo de ampliar sua maturidade (Rodrigues et al., 2014). Em seu estudo, estes autores indicaram que nas áreas em que pouca importância institucional é dada à IC, a eficiência dos produtos é evidentemente baixa; em locais em que tais processos estão terceirizados, isso é ainda mais agravante. Entretanto, nos departamentos em que a IC se articula de maneira mais consistente, seu valor circunstancial e estrutural para o negócio garante mais eficiência na tomada de decisão. Plessis e Gulwa (2016) afirmam que, para atingir o nível de sistematização ideal, é essencial que as práticas de IC evoluam e garantam sinergia com o gerenciamento estratégico da organização, e acreditam que os profissionais precisam de profunda compreensão das necessidades dos tomadores de decisão e 
do valor de decisão que associam à IC. Rodrigues e Riccardi (2007) acreditam que para uma empresa atingir nível relevante de maturidade em IC deve possuir uma infraestrutura de TI que permita sua estruturação como um sistema organizacional. Quanto maior o grau de maturidade, maior a capacidade competitiva da empresa em função das informações providas (Oliveira, Souza, Arenhardt \& Niveiros, 2017). Estes autores destacam que maturidade é um conceito de estrutura, formada de partes que definem a área de interesse. Assim, cada etapa do processo de IC compõe também o escopo da maturidade em IC, além de outros aspectos. Hedin e Thieme (2010) definem fatores-chave de sucesso para IC, e que podem servir de parâmetros complementares às etapas do Ciclo de IC, para o desenvolvimento e a aferição do grau de maturidade: i) processo; ii) organização; iii) escopo; iv) cultura organizacional; v) ferramentas e; vi) produtos. Janissek-Muniz, Salazar, Melati e Borges (2017) também publicaram estudo com fatores de sucesso para cada fase da atividade de IC: i) domínio/perímetro; ii) gestão, liderança e motivação; iii) atores e temáticas alvo; iv) coleta (recursos e fontes); v) seleção e pertinência das informações; vi) comunicação e compartilhamento informacional; vii) memória e registro; viii) criação de sentido; ix) difusão/disseminação; x) continuidade. Tais compilações de fatores críticos de sucesso são perceptíveis em organizações que já possuem um Ciclo de IC consolidado. Além disso, a Best Practices, LLC Research \& Consulting (2017) afirma que: a) o apoio da empresa para a IC é vital para o sucesso do processo; b) a IC deve possuir estrutura centralizada com grupos específicos de função descentralizada, reportando ao alto escalão executivo; c) os grupos de IC devem assumir papéis de liderança na formulação de estratégia competitiva. Chi-Yen (2018) credita a IC ao desempenho organizacional. Seu estudo mostra que existe uma relação entre a IC e o sistema de informação executiva: quando aprimorado, a alta administração é incentivada a construir conceitos e métodos de coleta de informações e escaneamento ambiental dos concorrentes. Além disso, sua pesquisa revelou que o conhecimento prévio dos gestores gera indicadores de desempenho superiores para a organização.

Rodrigues e Riccardi (2007) elaboraram um modelo que define níveis de maturidade em IC e os componentes de cada fase. No nível 1 ('Informal'), a IC é gerada informalmente, dissociada e independente. Existe estrutura de TI, mas embasa apenas algumas necessidades da organização. No nível 2 ('Formal'), os processos da IC são conhecidos, formalizados e os usuários têm percepção dos papéis e funções. Mas mesmo a existência de normatização não garante que as atividades sejam conhecidas e praticadas de maneira padronizada. Além disso, não é vista nesse nível a expertise no acesso às informações, dosagem e distribuição da inteligência. Quando as ações da IC fazem parte da cultura da empresa, estando integradas aos processos, elas se transformam em disciplina de observância. Essa fase é conhecida como nível 3 ('Disciplinado'), caracterizada pelo incentivo ao empreendedorismo corporativo rumo à inovação. O nível 4 ('Controlado') é fortemente marcado pelo estabelecimento de indicadores de desempenho para avaliar a eficácia da IC e sua operacionalização. Nessa fase "o controle passa a ser uma ferramenta administrativa para induzir ao cumprimento de metas e a um aumento da produtividade" (Rodrigues \& Riccardi, 2007, p.136). Quando a IC está consolidada como peça-chave para determinar as decisões estratégicas, está no nível 5 ('Otimizado'). Neste os participantes da IC têm por responsabilidade, além de executar todo o processo, contribuir para sua otimização, por ampliar as aplicações do produto da IC e por 
corrigir direcionamentos do processo. Nesse cenário, a expertise em IC depende das políticas de incentivo às operações, assim como do fomento ao empreendedorismo corporativo.

Esse modelo foi atualizado por Hedin e Thieme (2010), sendo que, para cada nível de maturidade em IC, definiram um papel do gerente de IC: nível 1('IC Informal') - o bombeiro; nível 2 ('IC Básica') - o iniciante; nível 3 ('IC Intermediária) - o coordenador; nível 4 ('IC Avançada') - o gerente; nível 5 ('IC de classe mundial') - o futurista. Os autores enfatizam que para que uma empresa evolua em níveis de maturidade é necessário que cada obstáculo seja superado, e mencionam que pular níveis pode ser difícil, por envolver a participação de muitas pessoas e fatores-chave de sucesso que precisam ser alcançados. Zuquetto e Beltrame (2012) também identificaram um conjunto de processos que devem evoluir pelos níveis de maturidade, tais como cultura organizacional, estrutura, envolvimentos dos funcionários e alta direção, e elaboraram uma escala de maturidade, de 1 ('Informal') a 5 ('Formal').

\section{Procedimentos Metodológicos}

Quanto aos fins, esta pesquisa se caracteriza como descritiva (Vergara, 2014). Quanto aos meios, caracteriza-se como um estudo de casos múltiplos (Yin, 2015), sendo utilizada a abordagem quantitativa (Creswell, 2010). As unidades de análise (Bressan, 2000) fazem referência às startups do San Pedro Valley, comunidade que surgiu com o objetivo de promover o compartilhamento de experiências entre alguns empreendedores de startups, que inicialmente se organizavam em reuniões informais em bares no bairro São Pedro, região centro-sul de Belo Horizonte. Desde 2011, marco de seu primórdio, o grupo ampliou e excedeu os limites geográficos da região. Não tem um líder oficial, configura-se como uma cultura de compartilhamento e por isso não tem formalização jurídica. As empresas se ajudam de maneira independente, semelhante ao Silicon Valley (Califórnia/EUA), de onde se originaram empresas de TI como Google, Facebook e Apple. As unidades de observação foram os empreendedores das startups da Comunidade San Pedro Valley, selecionados por amostragem não probabilística por conveniência (Marconi \& Lakatos, 1996), por serem eles os responsáveis por determinar a diretriz estratégica de suas empresas e garantir que os objetivos sejam alcançados. O universo inicial contou com uma base de dados de 452 startups listadas no site da Comunidade San Pedro Valley. Deste universo, 41 startups não possuíam informações para contato. Ao final, então, foram enviados 411 questionários estruturados, sendo que: i) 97 retornaram com a mensagem "destinatário não encontrado"; ii) 7 responderam que a startup não existe mais; iii) 5 abriram atendimentos automáticos. Dessa forma, o 'universo real' para contato resultou em 302 startups. Para reforçar o pedido de resposta do questionário enviado, buscou-se contato com cada uma dessas empresas, a partir de: i) mensagens individuais a 221 startups pelo comunicador do Facebook (Messenger); ii) contato via chat do site da empresa com 4 delas; iii) contato pelo aplicativo de conversas WhatsApp com 3 delas; iv) contato via telefone com 1 startup; v) novas mensagens por email para 73 startups as quais só possuíam este canal de comunicação.O link do questionário ficou disponível na plataforma Google Forms por exatos 30 dias. Foram coletadas, ao final, 93 respostas, mas 6 respondentes não assumiam posição estratégica na organização. Sendo assim, o número final da amostra foi de 87 respostas válidas, o que corresponde a um nível de confiança de $90 \%$, e margem de erro de mais ou menos $7 \%$. O questionário estruturado (Cervo, Bervian \& Da Silva, 2009) se deu a partir do modelo de Mafra Pereira, Carvalho, 
Jordão e Borges (2018). Para cada etapa do Ciclo de IC foram formuladas afirmativas que objetivaram medir o nível de concordância/discordância, por meio de escala do tipo Likert de 5 pontos (Silva \& Costa, 2014), sendo o valor '0' (zero) correspondente à opinião 'discordo totalmente' e o valor '4' (quatro) à opinião 'concordo totalmente', e permitindo uniformidade nas respostas e consequente padronização dos dados (Batista \& Campos, 2007). O questionário foi elaborado com 22 questões, sendo 17 questões pautadas sobre o Ciclo de IC, e 5 complementares, após a apresentação do conceito de IC (conforme referencial teórico) aos empreendedores. Foi aplicada análise fatorial (Field, 2009) para validação, e estatística básica (Pinheiro, Da Cunha, Carvajal \& Gomes, 2009) para análise dos dados obtidos.

\section{Apresentação, Análise e Discussão dos Resultados}

\subsection{Acompanhamento/Monitoramento do ambiente de negócios pelas Startups CSPV}

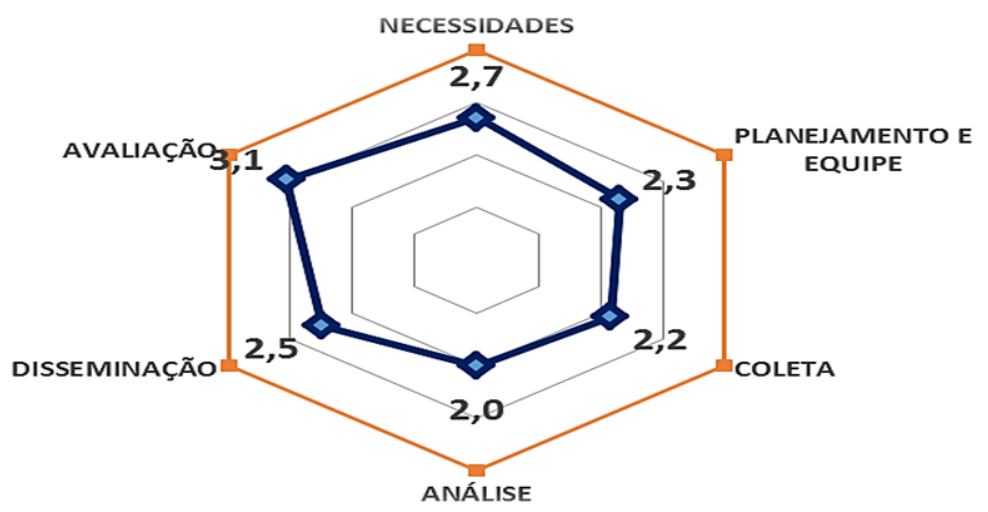

Figura 2 - Média das Dimensões do Ciclo de IC - Comunidade San Pedro Valley.

Fonte: Elaborado pelos autores (2019), com base em Mafra Pereira, Carvalho, Jordão e Borges (2018).

A $1^{\mathrm{a}}$ etapa ('Necessidades de Informações') apresentou média de 2,7, com destaque para a afirmativa de que nas startups da Comunidade San Pedro Valley os temas e tópicos-chave sobre o ambiente competitivo/de negócios a serem monitorados são conhecidos e bem definidos (média de 2,93). $\mathrm{O}$ avanço nesta etapa relaciona-se, exatamente, à necessidade de um processo mais estruturado para monitoramento do ambiente competitivo/de negócios.

Tabela 1 - Etapa 1: Necessidades de Informações

\begin{tabular}{l|c}
\hline \multicolumn{1}{c|}{ Questões } & Média \\
\hline Q1. Na minha empresa existe um processo estruturado para monitorar o ambiente competitivo/de negócios & 2,46 \\
\hline Q2. Na minha empresa os atores/stakeholders a serem monitorados são conhecidos e bem definidos & 2,74 \\
\hline $\begin{array}{l}\text { Q3. Na minha empresa os temas/tópicos-chave sobre o ambiente competitivo/de negócios a serem monitorados são } \\
\text { conhecidos e bem definidos }\end{array}$ & 2,93 \\
\hline
\end{tabular}

Fonte: Elaborado pelos autores, com base nos dados da pesquisa (2019).

Em relação à $2^{\mathrm{a}}$ etapa ('Planejamento e Equipe'), a média das startups da Comunidade San Pedro Valley foi de 2,3. Destaque para a afirmativa de que nas startups existe uma clara definição das fontes de informações a serem consultadas para a coleta de dados e informações sobre o ambiente competitivo/de negócios $(2,65)$. Por outro lado, a afirmativa de que nas startups existe equipe interna dedicada à busca e tratamento dos dados e informações obteve a menor média $(1,85)$. Por característica, as startups tendem a operar com recursos escassos e 
dependentes de investidores para fomento aos negócios. Por isso, muito do que é investido tende a não ser direcionado para processos de IC. Hedin e Thieme (2010) acreditam que no início das atividades de IC há somente um gestor, para depois evoluir para uma configuração complexa de grupos de direção, redes internas e externas para coleta, equipes de análise e suporte de TI. Portanto, possuir um time capaz de assumir essas responsabilidades é um desafio para as startups, pois trabalham com estrutura restrita de colaboradores que se desdobram em diversas funções (Zuquetto \& Beltrame, 2012).

Tabela 2 - Etapa 2: Planejamento e Equipe

\begin{tabular}{l|c}
\hline \multicolumn{1}{c|}{ Questões } & Média \\
\hline $\begin{array}{l}\text { Q4. Na minha empresa existe uma clara definição das fontes de informações a serem consultadas para a coleta dos dados e } \\
\text { informações sobre o ambiente competitivo/de negócios }\end{array}$ & 2,65 \\
\hline $\begin{array}{l}\text { Q5. Na minha empresa existe um planejamento dos recursos (humanos, financeiros, estruturais) a serem utilizados na busca } \\
\text { e tratamento dos dados e informações sobre o ambiente competitivo/de negócios }\end{array}$ & 2,43 \\
\hline $\begin{array}{l}\text { Q6. Na minha empresa existe uma equipe interna dedicada para a busca e tratamento dos dados e informações sobre o } \\
\text { ambiente competitivo/de negócios }\end{array}$ & 1,85 \\
\hline
\end{tabular}

Fonte: Elaborado pelos autores, com base nos dados da pesquisa (2019).

Em relação à $3^{\text {a }}$ etapa ('Coleta das Informações'), a média das startups foi de 2,2. Destaque para a afirmativa de que o processo de coleta de dados e informações sobre o ambiente competitivo/de negócios é realizado com forte apoio de sistemas e TI $(2,89)$. Por característica natural, as startups da Comunidade San Pedro Valley são do segmento de tecnologia, o que facilita não somente a busca, mas a estruturação de dados e informações coletadas em seu ambiente de negócios. Inclusive, várias delas têm como core business a busca e o tratamento de informações para negócios. Por outro lado, a média correspondente à afirmativa de que as startups contam com a participação de pessoas externas/especialistas no processo de coleta de dados e informações é baixa $(1,43)$. Este é um ponto a ser desenvolvido pelas startups, pois mesmo sendo empresas de pequeno porte e com estrutura de custos enxuta, o foco no relacionamento com outras empresas e profissionais externos é essencial para a alavancagem de seus negócios, não apenas para a atividade de IC. Canongia et al. (2001) alerta que os dados são coletados segundo critérios como acessibilidade, multidisciplinaridade, custo, qualidade do conteúdo, cobertura e abrangência, e que para satisfazê-los, é preciso investir na sistematização da busca e na validação dos dados (Motte, 2007). Portanto, há possibilidade de melhoria de ambos os aspectos avaliados nesta etapa.

Tabela 3 - Etapa 3: Coleta das Informações

\begin{tabular}{l|c}
\multicolumn{1}{c|}{ Questões } & Média \\
\hline $\begin{array}{l}\text { Q7. Na minha empresa o processo de coleta de dados e informações sobre o ambiente competitivo/de negócios é realizado } \\
\text { com forte apoio de sistemas e tecnologias da informação }\end{array}$ & 2,89 \\
\hline $\begin{array}{l}\text { Q8. Na minha empresa o processo de coleta de dados e informações sobre o ambiente competitivo/de negócios conta com a } \\
\text { participação de pessoas externas/especialistas/de outras empresas }\end{array}$ & 1,43 \\
\hline Fonte: Elaborado pelos autores, com base nos dados da pesquisa (2019).
\end{tabular}

Fonte: Elaborado pelos autores, com base nos dados da pesquisa (2019).

Em relação à $4^{\mathrm{a}}$ etapa ('Análise das Informações'), a média das startups foi de 2,0 (a pior quando comparada às demais etapas do Ciclo de IC). Destaque para a afirmativa de que nas startups existe uma equipe interna com competência para analisar os dados e informações coletados sobre o ambiente competitivo/de negócios $(2,70)$. Pode-se inferir, dado que os respondentes foram os próprios empreendedores das startups, que eles se consideram capazes de realizarem a análise e de perceberam sinais (positivos e/ou negativos) advindos do 
mercado. Por outro lado, a média mais baixa da etapa correspondeu à afirmativa de que as startups não contam com a participação de pessoas externas/especialistas para análise dos dados e informações $(1,13)$, sendo esta, inclusive, a menor média dentre todas as alternativas avaliadas em todas as etapas do Clico de IC. Tal média corrobora a falta de maior interação das startups com atores externos aos seus negócios, o que, mais uma vez, vai contra à natureza deste tipo de empresa em fazer parte e se desenvolver via modelos em rede. Vale destacar que as startups operam com uma estrutura enxuta, permitindo que os líderes trabalhem mais próximos. Esse é um ponto interessante e a favor das startups (ponto de vista interno). Assim, elas têm duas possibilidades para melhoria dos aspectos desta fase de análise da IC: i) qualificar os próprios recursos internos ou; ii) contratar empresas especialistas e/ou terceiros. Para isso é necessário tempo e recursos financeiros, sendo que nenhuma dessas possibilidades tende a ser o foco inicial dessas organizações. Finalmente, para que a etapa de análise alcance níveis mais elevados de maturidade em IC requer-se que as startups façam diagnósticos profundos, apresentações e relatórios personalizados, além de investigações qualitativas. $\mathrm{O}$ investimento em softwares e modelos estatísticos pode, também, garantir que os analistas da IC utilizem seu tempo em atividades que agreguem mais valor à Inteligência.

Tabela 4 - Etapa 4: Análise das Informações

\begin{tabular}{l|c}
\hline \multicolumn{1}{c|}{ Questões } & Média \\
\hline $\begin{array}{l}\text { Q9. Na minha empresa existe uma equipe interna com competência para analisar os dados e informações coletados sobre o } \\
\text { ambiente competitivo/de negócios }\end{array}$ & 2,70 \\
\hline $\begin{array}{l}\text { Q10. Na minha empresa as análises dos dados e informações coletados sobre o ambiente competitivo/de negócios contam } \\
\text { com a participação de pessoas externas/especialistas à organização }\end{array}$ & 1,13 \\
\hline $\begin{array}{l}\text { Q11. Na minha empresa são utilizados modelos/metodologias para análises dos dados e informações coletados sobre o } \\
\text { ambiente competitivo/de negócios }\end{array}$ & 2,20 \\
\hline
\end{tabular}

Fonte: Elaborado pelos autores, com base nos dados da pesquisa (2019).

$\mathrm{Na}$ etapa de 'Disseminação das Informações' ( $5^{\mathrm{a}}$ etapa), a média das startups da Comunidade San Pedro Valley foi de 2,5, e ambas as afirmativas obtiveram notas similares. Um dos objetivos da IC é permitir que decisões sejam tomadas com a máxima assertividade para que a organização se mantenha competitiva no mercado. Assim, o produto gerado pelas análises deve atender às necessidades dos tomadores de decisão e, inclusive, da maneira como gostariam que fosse apresentado. As médias demonstram que as startups produzem diferentes tipos de relatórios sobre o mercado de atuação, e que os mesmos são utilizados, em tempo hábil, para a tomada de decisão. Um ponto que pode ser questionado nestes resultados é sobre a qualidade dos produtos de IC, visto que a etapa de 'Análise das Informações', a qual, em tese, deveria suportar a produção de tais produtos, é aquela que mais carece de desenvolvimento. Em outras palavras, pode-se supor que os produtos informacionais utilizados pelos decisores das startups entrevistadas sejam superficiais e limitados a questões do dia a dia e de curto prazo destas empresas.

Tabela 5 - Etapa 5: Disseminação das Informações

\begin{tabular}{l|c}
\multicolumn{1}{c|}{ Questões } & Média \\
\hline $\begin{array}{l}\text { Q12. Na minha empresa são produzidos diferentes tipos de relatórios/produtos de análise de dados e informações sobre o } \\
\text { ambiente competitivo/de negócios para os responsáveis pela formulação de estratégias e tomada de decisão }\end{array}$ & 2,50 \\
\hline $\begin{array}{l}\text { Q13. Na minha empresa os responsáveis pela formulação de estratégias e tomada de decisão recebem os dados e } \\
\text { informações sobre o ambiente competitivo/de negócios com tempo necessário para refletirem e decidirem sobre o que fazer }\end{array}$ & 2,48 \\
\hline Fonte: Elaborado pelos autores, com base nos dados da pesquisa (2019). &
\end{tabular}


A $6^{\text {a }}$ etapa de 'Avaliação das Informações' se propõe a mensurar qual efetividade as análises tiveram em relação às estratégias e decisões da organização, ou seja, quais os resultados alcançados com o produto da IC. A média das startups nesta etapa foi de 3,1 (a melhor quando comparada com as demais etapas do Ciclo de IC). O destaque foi a afirmativa de que nas startups as informações disponibilizadas contribuem para que a inovação aconteça $(3,20)$, sendo esta a melhor média dentre todas as alternativas avaliadas referentes ao Ciclo de IC. De certo modo, este índice positivo reflete a própria natureza das startups da Comunidade San Pedro Valley, de serem empresas do segmento de TI com potencial de inovação acelerado. As demais afirmativas também obtiveram índices positivos. Em linhas gerais, os respondentes afirmam que as informações disponibilizadas para formulação de estratégias, tomada de decisão e inovação são de fato utilizadas e consideradas importantes/valorizadas.

Tabela 6 - Etapa 6: Avaliação das Informações

\begin{tabular}{l|c}
\multicolumn{1}{c|}{ Questões } & Média \\
\hline $\begin{array}{l}\text { Q14. Na minha empresa as análises realizadas sobre o ambiente competitivo/de negócios contribuem para a formulação das } \\
\text { estratégias }\end{array}$ & 3,11 \\
\hline $\begin{array}{l}\text { Q15. Na minha empresa as análises realizadas sobre o ambiente competitivo/de negócios contribuem nos processos de } \\
\text { tomada de decisão }\end{array}$ & 3,04 \\
\hline $\begin{array}{l}\text { Q16. Na minha empresa as análises realizadas sobre o ambiente competitivo/de negócios contribuem para que a inovação } \\
\text { aconteça (em produtos, serviços, processos, novos negócios) }\end{array}$ & 3,20 \\
\hline $\begin{array}{l}\text { Q17. Na minha empresa as pessoas envolvidas com a coleta, análise e entrega dos dados e informações sobre o ambiente } \\
\text { competitivo/de negócios são reconhecidas e valorizadas }\end{array}$ & 2,93 \\
\hline
\end{tabular}

Fonte: Elaborado pelos autores, com base nos dados da pesquisa (2019).

Percebe-se que as startups da Comunidade San Pedro Valley têm conhecimento sobre suas necessidades e utilizam as informações obtidas nos seus processos estratégicos, de tomada de decisão e de inovação. Os pontos de melhoria são nas etapas mais operacionais do processo de IC (coleta e análise). A melhoria destas etapas poderia incrementar, ainda mais, a aplicação e os resultados obtidos. Assim, afirma-se que o $1^{\circ}$ objetivo deste trabalho, que era identificar, através da opinião de seus empreendedores, como as startups da Comunidade San Pedro Valley atualmente acompanham/monitoram seu ambiente de negócios, foi devidamente cumprido.

\subsection{Nível de Conhecimento dos gestores das Startups CSPV sobre a IC e seus processos}

Além das afirmativas correspondentes às 6 etapas do Ciclo de IC, foram apresentadas mais 5 com base na literatura que ajudam a embasar o grau de maturidade em IC.

Tabela 7 - Questões Complementares

\begin{tabular}{l|c}
\multicolumn{1}{c|}{ Questões } & Média \\
\hline Q18. Na minha empresa os responsáveis pela formulação das estratégias e tomada de decisão conhecem o conceito de IC & 2,50 \\
\hline Q19. Na minha empresa os colaboradores em geral conhecem o conceito de Inteligência Competitiva & 1,96 \\
\hline Q20. Na minha empresa existe um processo de Inteligência Competitiva conforme a definição acima & 2,09 \\
\hline Q21. Na minha empresa a Inteligência Competitiva está integrada com todos os setores estratégicos & 1,89 \\
\hline Q22. A minha empresa é experiente no processo de Inteligência Competitiva & 1,46 \\
\hline
\end{tabular}

Fonte: Elaborado pelos autores, com base nos dados da pesquisa (2019).

Após a apresentação do conceito de IC, baseado na literatura, a afirmativa correspondente ao conhecimento do conceito por parte dos decisores das startups da Comunidade San Pedro Valley apresentou a maior média $(2,50)$, confirmando as análises 
anteriores e a condição dos entrevistados como os principais responsáveis pelas estratégias e tomadas de decisão de suas empresas. Pode-se inferir que as startups (em especial, seus empreendedores) desenvolvem processos de monitoramento de mercado, mesmo de forma empírica ou intuitiva, sem saber que de fato estão realizando IC, indo de encontro ao que afirmam Rodrigues, Volpp e Rechziegel (2014). Este resultado também se justifica conforme Pinheiro (2016), ao relatar que os gestores, nesse caso, atuam como cérebro da organização, sendo responsáveis por guiar todas as estratégias do negócio. Assim, tomam todas as decisões que influenciam a sobrevivência da startup. A afirmativa que obteve a menor média foi relacionada à falta de experiência da empresa no processo de IC $(1,46)$, resultado que confirma que a IC, no contexto das startups, é realizada quase exclusivamente pelos próprios decisores, e quando realizada, é nova. Por outro lado, considerando que as startups são empresas iniciantes e de pequeno porte, tal resultado acaba sendo esperado neste contexto. Por último, pesquisa realizada por Chi-Yen (2018) revelou que o discernimento dos gerentes sobre a IC gera indicadores de desempenho superiores para as organizações. Portanto, é importante que os gestores saibam seu conceito e, além disso, também os colaboradores, para que uma rede seja construída e fomentada a cultura da IC. Dessa maneira, afirma-se que o $2^{\circ}$ objetivo deste trabalho, que era identificar o nível de conhecimento dos gestores das startups da Comunidade San Pedro Valley sobre a IC e seus processos (comparativamente aos modelos de IC propostos pela literatura), foi devidamente cumprido.

\subsection{Proposição de modelo para averiguação do Grau de Maturidade em IC para Startups}

Conforme destacado no referencial teórico, alguns autores apresentam propostas para avaliação do grau de maturidade em IC, mas todas de caráter qualitativo e subjetivo. Assim, buscou-se, a partir dos resultados obtidos, evoluir nestas definições, propondo um modelo quantitativo para aferição do grau de maturidade em IC nas startups pesquisadas. Neste modelo, considerou-se a classificação em 4 níveis, com seus respectivos conceitos (Tabela 8):

Tabela 8 - Níveis para aferição do Grau de Maturidade em IC nas Startups CSPV

\begin{tabular}{c|l|c}
\hline Nível 1 & Informal (ad hoc) & $0,00-1,49$ \\
\hline Nível 2 & Básico (Iniciante) & $1,50-2,49$ \\
\hline Nível 3 & Intermediário (Estruturado) & $2,50-3,49$ \\
\hline Nível 4 & Avançado (Otimizado) & $3,50-4,00$. \\
\hline
\end{tabular}

Fonte: Elaborada pelos autores (2019).

O Nível 1 ('Informal/ad hoc') sugere empresas nas quais a IC atende a apenas algumas necessidades mais urgentes e de curto prazo, geralmente realizada sob demanda. Não há recursos, escopo e processo definidos. O Nível 2 ('Básico/Iniciante') sugere empresas nas quais a IC já surge com os primeiros aspectos de normalização, onde os usuários já possuem percepção dos seus papéis e funções. Apesar de conseguirem se aprofundar em alguns aspectos básicos do ambiente de negócios, ainda atuam sob demanda. Não é registrada nessa fase expertise no acesso a informações, análise e distribuição. Além disso, possuem baixo grau de orientação futura e cultura de IC. O Nível 3 ('Intermediário/Estruturado') sugere empresas com processos internos de IC mais estruturados, existência de redes de inteligência internas e externas, sendo inserida nas decisões estratégicas. É possível perceber a existência 
de uma cultura da IC fortemente marcada pelo estabelecimento de indicadores para avaliar sua operacionalização e eficácia. O Nível 4 ('Avançado/Otimizado') sugere empresas que possuem experiência nos processos de IC, a qual ampara todos os processos decisórios e de inovação estratégica. Ainda, possuem uma cultura baseada na disciplina de observância, com participação de todos e apoio do mais alto nível, sendo a IC integrada aos processos organizacionais-chave e fundamentada por produtos sofisticados, com alto grau de orientação futura. Como proposta de aferição do grau de maturidade em IC, sugere-se a seguinte metodologia: i) a média de cada uma das 6 etapas do Ciclo de IC teria peso 1 no cálculo final do grau de maturidade, mas a média das questões complementares, que representam as características das empresas com alto grau de maturidade em IC, teria peso 2; ii) quanto aos intervalos, sugere-se um intervalo de 0,00 a 1,40 para o Nível 1, de 1,50 a 2,40 para o Nível 2, de 2,50 a 3,40 para o Nível 3, e de 3,50 a 4,00 para o Nível 4.

Aplicando-se a metodologia proposta, o grau de maturidade auferido para as startups da Comunidade San Pedro Valley foi de 2,40, caracterizando a maturidade como 'Básico/Iniciante' (Nível 2), mas no limite para o Nível 3 ('Intermediário/Estruturado'). Este resultado confirma as análises e percepções obtidas nas etapas do Ciclo de IC, e nas questões complementares aplicadas. Conforme destacado por Zuquetto e Beltrame (2012), este nível de maturidade indica que o processo de tomada de decisão é sustentado por informações oportunas, com parâmetros e indicadores de desempenho e inspeção da relevância do produto, e essa foi a etapa mais bem avaliada entre as demais. No contexto das startups é comum que hipóteses sejam validadas, e caso o feedback seja negativo, o interpretem como sendo um evento de aprendizado e oportunidade de mudança do negócio, e não como uma crise ou um problema organizacional. Ou seja, o ato de avaliar é uma atividade que faz parte da rotina das startups, pois precisam rapidamente obter resultado por meio de suas ações. De qualquer forma, o $3^{\circ}$ objetivo deste trabalho, que era propor um modelo para averiguação do grau de maturidade em IC a ser adotado pelas startups, foi devidamente cumprido.

\section{Considerações Finais}

A partir dos resultados obtidos, considera-se que todos objetivos propostos foram devidamente cumpridos. De forma geral, as startups da Comunidade San Pedro Valley possuem práticas pouco estruturadas e não formalizadas de IC. Das seis etapas do Ciclo de IC, destaque para a 'Identificação das Necessidades Informacionais' e a 'Avaliação'. As menores médias corresponderam às etapas de 'Coleta' e de 'Análise', etapas críticas do processo de IC que não são executadas conforme apregoa a literatura. A partir do modelo proposto para averiguação do grau de maturidade das startups da Comunidade San Pedro Valley, obteve-se a nota 2,40, traduzindo o limite entre o nível básico ('iniciante') e o intermediário ('estruturado'), refletindo uma nota regular, dada as características destas empresas em serem mais orgânicas e menos estruturadas, em termos de gestão. Vale ressaltar que os métodos tradicionais de gerenciamento não se aplicam ao contexto das startups, pois estas são projetadas para terem uma estrutura enxuta, com orçamentos reduzidos e alto senso de urgência. Por isso, o resultado encontrado não deve ser visto como preocupante, e uma pergunta se coloca a partir deste ponto de vista: as startups da Comunidade San Pedro Valley precisariam, de fato, atingir níveis elevados de maturidade em IC? A flexibilidade para as startups é essencial, pois mudanças são realizadas em resposta a feedbacks adquiridos do 
mercado, não compensando, dessa forma, terem estruturas e processos rígidos que diminuam a flexibilidade das ações e estratégias. Dessa forma, possuir um grau de maturidade em IC situado na fronteira entre o nível básico ('iniciante') e o intermediário ('estruturado') já poderia ser suficiente para garantir adequado apoio dos princípios da IC ao crescimento competitivo das startups. O essencial é que tenham entendimento sobre a IC e suas vantagens para evolução do negócio. Mesmo assim, as startups podem aprimorar os processos relacionados à coleta e análise de dados e informações, aproveitando-se das tecnologias que já detêm. Por serem empreendimentos de base tecnológica, possuem recursos que permitem desenvolvimento de soluções capazes de não só de coletar, mas processar dados em tempo real, realizar análises complexas e projeções de cenários para decisões mais assertivas. Assim, o grau de maturidade em IC poderá ser maior sem que para isso sejam necessários altos investimentos financeiros e de tempo. A proposição de um modelo para aferição do grau de maturidade em IC e consequente escala de medição se constituíram nas principais contribuições desta pesquisa, permitindo a avaliação quantitativa de modelos de maturidade que até então só se apresentavam a partir de critérios qualitativos e subjetivos, auferindo resultados mais assertivos. Evidente que tal proposição necessita ser validada também em outras comunidades de startups, bem como em organizações de diferentes portes, e de modelos de gestão diferentes dos adotados pelas startups, sendo esta uma das importantes recomendações para trabalhos futuros. Além disso, os resultados obtidos também contribuem, como previsto, à comunidade acadêmica conhecimento sobre o uso e grau de aplicação da IC no contexto das startups, em contraponto à maior parte das pesquisas sobre IC em organizações de grande porte ou empresas com modelos de negócios tradicionais, mesmo de pequeno porte. Também contribui para o aprimoramento dos modelos de gestão das startups, ressaltando-se práticas inovadoras em IC, de forma sistêmica e formal, com vistas a tomadas de decisão mais assertivas para alcance de vantagem competitiva, mais sustentáveis e duradouras, com resultados eficientes, mensuráveis e gerenciados sistematicamente. Ainda, permite conhecer, cientificamente, sobre as práticas informacionais estratégicas das startups da Comunidade San Pedro Valley e sobre o conhecimento dos seus empreendedores a respeito de práticas inovadoras de gestão das informações estratégicas que possam levar à vantagem competitiva. Como limitações do trabalho, ressalta-se a dificuldade de contato com a totalidade dos empreendedores das startups da Comunidade San Pedro Valley, mesmo tendo sido esgotados todos os meios possíveis para tal, o que acabou limitando a amostra final. Ressalva-se também o cuidado para a não generalização dos resultados obtidos, obtidos junto ao contexto das startups representantes do segmento de TI, apesar destes colaborarem para os diversos campos teóricos e práticos do tema.

\section{Referências}

Alvarenga Neto, R.C.D. (2008). Gestão do conhecimento em organizações: proposta de mapeamento conceitual integrativo. São Paulo: Saraiva.

Amaral, R.M., Brito, A.G.C., Lima, L.I.L.F., Rocha, K.G.S, \& Quoniam, L. (2016). Panorama da inteligência competitiva no Brasil: os pesquisadores e a produção científica na plataforma Lattes. Perspectivas em Ciência da Informação, $21(4), 97-$ 120.

Amaral, R.M., Garcia, L.G., Faria, L.I.L., \& Aliprandini, D.H. (2008). Modelo para o mapeamento de competências em equipes de inteligência competitiva. Revista Ciência da Informação, 37(2), 7-19.

ABRAIC - Associação Brasileira dos Analistas de Inteligência Competitiva. (2018). História da Inteligência Competitiva no Brasil. Disponível em: 〈http://www.abraic.org.br〉. Acesso em 13 jun. 2019.

Baierle, I.C., Frozza, R., Nara, E.O.B., \& Kipper, L.M. (2011). O Ciclo da Produção de Inteligência como apoio à estratégia de tomada de decisão organizacional. Revista Produção Online, 11(4), 1086-1113. 
Batista, M.N., \& Campos, D.C. (2007). Metodologias de pesquisa em ciências: análises quantitativa e qualitativa. Rio de Janeiro: LTC, 80-89.

Bernhardt, D. (2004). Competitive Intelligence: how to acquire and use corporate intelligence and counter-intelligence. London: Prentice Hall.

Best Practices, LLC Research \& Consulting (2018). Managing the Competition: Turning Competitive Intelligence into Strategy. Disponível em: < https://www.best-in-class.com/bestp/domrep.nsf/products/managing-the-competition-turningcompetitive-intelligence-into-strategy?opendocument $>$. Acesso em 13 mai.2019.

Blank, S. (2015). What Do I Do Now? The Startup Lifecycle. Disponível em: < https://steveblank.com/2015/02/12/what-do-ido-now/>. Acesso em 15 abr. 2019.

Bressan, F. (2000). O Método do Estudo de Caso. Administração On Line, 1(1), jan./mar.

Calof, J.L., \& Wright, S. (2008). Competitive intelligence: A practitioner, academic and interdisciplinary perspective. European Journal of Marketing, 42(7/8), 717-730.

Canongia, C., Lamb, C., Carvalho, C.S.P.. \& Silva, V.S. (2001). Convergência da Inteligência Competitiva com construção de visão de futuro: proposta metodológica de sistema de informação estratégica (SIE). DataGramaZero - Revista de Ciência da Informação, 2(3), jun.

Capuano, E.A., Casaes, J., \& Costa, J.R. (2009). Inteligência Competitiva e suas conexões epistemológicas com Gestão da Informação e Conhecimento. Ciência da Informação, 38(2), 19-34, maio/ago.

Cervo, A.L., Bervian, P.A., \& Da Silva, R. (2009). Metodologia Científica. 6a. ed. São Paulo: Pearson Prentice Hall.

Chi-Yen, Y. (2018). Measuring organizational impacts by integrating competitive intelligence into executive information system. Revista Intelligent Manufacturing, 29(3), 533-547.

Coutinho, M.L.G., \& Ramos, H.R. (2015). Monitoramento Ambiental em empresa de pequeno porte: caso Run\&Fun Assessoria Esportiva. In: IV SINGEP - Simpósio Internacional de Gestão de Projetos, Inovação e Sustentabilidade, São Paulo. Anais Eletrônico... São Paulo: UNINOVE.

Creswell, J.W. (2010). Projeto de Pesquisa: Método Qualitativo, Quantitativo e Misto. Porto Alegre: Bookman.

Dishman, P.L., \& Calof, J.L. (2008). Competitive intelligence: A multiphasic precedent to marketing strategy. European Journal of Marketing, 42(7), 766-785.

Field, A. (2009). Descobrindo a estatística usando o SPSS. 2a. ed. Porto Alegre: Artmed.

Garcia, L.G., Bessi, N.C., \& Reis, F.N. (2013). Caracterização de Redes Informacionais Interorganizacionais de Profissionais de Inteligência Competitiva. In: XIV ENANCIB - Encontro Nacional de Pesquisa em Ciência da Informação, Florianópolis. Anais Eletrônico... Florianópolis: UFSC.

Gomes, E., \& Braga, F. (2004). Inteligência competitiva: como transformar informação em um negócio lucrativo. Rio de Janeiro: Elsevier.

Hedin, H., \& Thieme, J. (2010). From firefighters to futurists: A practical roadmap for CI development. Competitive Intelligence Magazine, 13(1), 25.

Herring, J.P. (1999). Key Intelligence Topics: A Process to Identify and Define Intelligence Needs. Competitive Intelligence Review, 10(2), 4-14.

Janissek-Muniz, R., Salazar, F., Melati, C., \& Borges, N. (2017). Fatores críticos de sucesso na condução de projetos de inteligência estratégica. XX SEMEAD - Seminários em Administração, São Paulo. Anais Eletrônico... São Paulo: FEA/USP.

Mafra Pereira, F.C. (2018). Evaluation of the business environment for use of information in the definition of business strategies. Reuna, 23(3), 32-53, Jul./Sept.

Mafra Pereira, F.C. (2016). Fontes de Informação para Negócios: análise sobre frequência, relevância e confiabilidade, baseada em estudo empírico com empresários e gestores organizacionais. Perspectivas em Ciência da Informação, 21(2), 100-119, abr./jun.

Mafra Pereira, F.C., \& Santos, M.G.A. (2015). Inteligência Competitiva na Indústria Alimentícia: Práticas adotadas e Proposta de Estruturação da IC em uma empresa de Processamento Mínimo de Frutas e Hortaliças de Minas Gerais. Revista Inteligência Competitiva, 5(4), 1-28, set./dez.

Mafra Pereira, F.C., Carvalho, R.B., \& Jordão, R.V.D. (2016). Análise do Ciclo de Inteligência Competitiva em Arranjos Produtivos Locais: Estruturação e Implantação do Bureau de Inteligência Competitiva do APL de Software de Belo Horizonte. Revista Inteligência Competitiva, 6(1), 139-164, jan./mar.

Mafra Pereira, F.C., Carvalho, R.B., Jordão, R.V.D., \& Borges, M.A. (2018). Inteligência Competitiva em Centrais de Negócios: proposição de modelo estruturante para empreendimentos coletivos e redes interorganizacionais. Revista Inteligência Competitiva, 8(1), 1-27, abr./jun.

Mafra Pereira, F.C., Jeunon, E.E., Barbosa, R.S., \& Duarte, L.C. (2018). Inteligência Competitiva como suporte à Estratégia Empresarial em micro e pequenas empresas: um estudo na Aerotrópole de Belo Horizonte. Revista Ibero-Americana de Estratégia, 17(1), 93-111.

Marconi, M.A., \& Lakatos, E.M. (1996). Técnicas de pesquisa: planejamento e execução de pesquisas, amostragens e técnicas de pesquisa, elaboração, analise e interpretação de dados. 3.ed. São Paulo Atlas.

Martre, H. (1994). Intelligence économique et stratégie des enterprises. Paris: Commissariat général du Plan. 
Miller, J. (2002). O Milênio da Inteligência Competitiva. Porto Alegre: Bookman.

Motte, M. (2007) Relatório do Seminário Internacional Inteligência Estratégica. Disponível em: < https://pt.scribd.com/document/35626799/Inteligencia-estrategica>. Acesso em 18 jul. 2019.

Oliveira, J.R., Souza, N., Arenhardt, R.L., \& Niveiros, S.I. (2017). Nível de Maturidade da Inteligencia Competitiva: Um estudo nas empresas Agropecuárias de Rondonópolis que possuem Controladoria. In: VI SINGEP - Simpósio Internacional de Gestão de Projetos, Inovação e Sustentabilidade, São Paulo. Anais Eletrônico... São Paulo: UNINOVE.

Oliveira, P., Gonçalves, C., \& Mendes de Paula, E. (2011). Diretrizes para a condução de uma atividade de inteligência competitiva: uma análise preliminar. Revista Inteligência Competitiva, 1(3), 257-272.

Oliveira, P.H., \& Sade, W. (2016). Inteligência Competitiva no contexto das empresas mineiras de artefatos de estanho. Perspectivas em Ciência da Informação, 21(1), 23-41, jan./mar.

Oliveira, P.H., \& Teles, E.L. (2015). Relações de dependência informacional entre os processos de administração estratégica e de inteligência competitiva. Revista Inteligência Competitiva, 5(2), 17-39, abr./jun.

Panizzon, M. (2010). Envolvimento da alta direção e inteligência competitiva: uma análise sobre suas relações em organizações de médio e de grande porte da Serra Gaúcha - Brasil. Caxias do Sul: UCS, 2010. Disponível em: < http://tede.ucs.br/tde_arquivos/5/TDE-2010-12-07T081340Z-402/Publico/Dissertacao\%20Mateus\%20Panizzon.pdf >. Acesso em 29 jun. 2019.

Passos, A. (2007). Inteligência Competitiva para Pequenas e Médias Empresas. LCTE Editora.

Pereira, C.E., \& Perez, G.A. (2015). Captura de Sinais do Ambiente Externo como elemento para o Processo de Inovação em Micro e Pequenas Empresas. In: IV SINGEP - Simpósio Internacional de Gestão de Projetos, Inovação e Sustentabilidade, São Paulo. Anais Eletrônico... São Paulo: UNINOVE.

Pereira, E.C. (Org.). (2013). Conhecimento, Estratégia e Informação: três constructos que se entrelaçam na gestão organizacional. 1a. ed. Curitiba: Editora Appris.

Pinheiro, J.I.D., Cunha, S.B., Carvajal, S.R., \& Gomes, G.C. (2009). Estatística Básica: a arte de trabalhar com dados. Rio de Janeiro: Elsevier.

Pinheiro, L. (2016). Ecossistemas de startups: o caso do Cesar com tecnologia da informação. Revista Fonte, Ano 13, 16(62).

Plessis, T.D.,\& Gulwa, M. (2016). Developing a competitive intelligence strategy framework supporting the competitive intelligence needs of a financial institution's decision makers. South African Journal of Information Management, 18(2),1-8.

Prescott, J.E., \& Miller S.H. (2002). Inteligência competitiva na prática: estudos de casos diretamente do campo de batalha. Rio de Janeiro: Campus.

Ries, E. (2012). A startup enxuta: como os empreendedores atuais utilizam a inovação contínua para criar empresas extremamente bem-sucedidas. São Paulo: Lua de Papel.

Rodrigues, L.C., \& Riccardi, R. (2007). Inteligência competitiva: nos negócios e organizações. Maringá: Unicorpore.

Rodrigues, L.C., Rechziegel, W., Esteves, G., \& Riscarolli, V. (2012). Inteligência competitiva como instrumento de inovação nos processos de negócio. Revista Gestão Organizacional, 5(2), 229-241.

Rodrigues, L.C., Volpp, J., \& Rechziegel, W. (2014). Maturidade organizacional em inteligência competitiva: o caso de uma instituição financeira brasileira. Revista de Ciências da Administração, 16(38), 126-139.

SEBRAE, Serviço Brasileiro de Apoio às Micro e Pequenas Empresas. Site. 2019. Disponível em: < https://www.sebrae.com.br/Sebrae/Portal\%20Sebrae/Estudos\%20e\%20Pesquisas/Participacao\%20das\%20micro\%20e\%20 pequenas\%20empresas.pdf>. Acesso em 27 jul. 2019.

Silva, S.D., \& Costa, F.J. (2014). Mensuração e Escalas de Verificação: uma Análise Comparativa das Escalas de Likert e Phrase Completion. PMKT - Revista Brasileira de Pesquisas de Marketing, Opinião e Mídia, 15, 1-16, out.

Starec, C. (2012). Gestão da Informação, Inovação e Inteligência Competitiva: como transformar a informação em vantagem competitiva nas organizações. São Paulo: Saraiva.

Startup Base Public Stats (2019). Estatísticas das Startups Brasileiras. Disponível em: < https://startupbase.com.br/stats>. Acesso em 08 jul. 2019.

SCIP - Strategic and Competitive Intelligence Professionals (2019). About SCIP. Disponível em: $\langle$ http://www.scip.org/?page=AboutSCIP $>$. Acesso em 27 jul. 2019.

Teixeira, R., \& Souza, C. (2017). Evolução da inteligência competitiva com base em estudo métrico de sua literatura. Perspectivas em Ciência da Informação, 22(1), 170-185.

Teixeira, T.M.C., \& Valentim, M.L.P. (2016). Inteligência Competitiva Organizacional: um estudo teórico. Perspectivas em Gestão \& Conhecimento, 6(Número Especial), 3-15, jan.

Terra, J.C.C. (2005). Gestão do conhecimento: o grande desafio empresarial. 5a. ed. São Paulo: Negócio.

Vergara, S.C. (2014). Projetos e Relatórios de Pesquisa em Administração. 15a. ed. São Paulo: Atlas

Vitorino, A.H., \& Garcia, L.G. (2013). Inteligência Competitiva na ampliação da efetividade da publicidade de Micro e Pequenas Empresas. In: XIV ENANCIB - Encontro Nacional de Pesquisa em Ciência da Informação, Florianópolis. Anais Eletrônico... Florianópolis: UFSC.

Yin, R.K. (2015). Estudo de casos: planejamento e métodos. 5a. ed. Porto Alegre: Bookman.

Zuquetto, R.D., \& Beltrame, A. (2012). Modelo de maturidade em inteligência competitiva. Revista Global Manager Acadêmica, 1(2). 